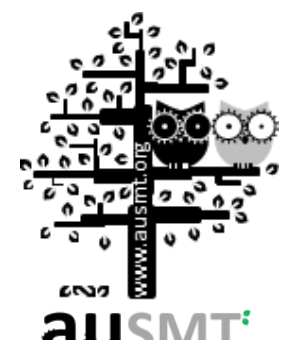

\title{
Music Play Using a Vibraphone with a Humanoid Robot as Interaction Training for Autistic Children
}

\author{
Ying-Hua Peng1, Ming-Liang Wang², Norbert Michael Mayer ${ }^{1,3 *}$, \\ Yu-Fen Peng ${ }^{1}$, and Joanna Kossewska ${ }^{4}$ \\ ${ }^{1}$ Department of Electrical Engineering, National Chung Cheng University, Taiwan \\ ${ }^{2}$ Asian Institute of TeleSurgery, Taiwan \\ ${ }^{3}$ Advanced Institute of Manufacturing with High-tech Innovations (AIM-HI), National Chung Cheng University, Taiwan \\ ${ }^{4}$ Department of Psychology, Pedagogical University of Cracow, Poland \\ (Received 9 August 2017; Accepted 28 September 2017; Published on line 1 March 2018) \\ *Corresponding author: nmmayer@gmail.com \\ DOI: 10.5875/ausmt.v8i1.1582
}

Abstract: Since 1998 robots have been used as social mediators that interact with autistic children. In this paper, we use music as a mediator between a robot and an autistic child. The robot plays a music interaction game by using a vibraphone, what might be seen as a kind of music therapy. The purpose of this work was to provide a robot and other multi-media interaction equipment as an interactive tool for professionals to reach the attention of their autistic pupils. The equipment has been used in a special care school in Taiwan. In this paper we focus on the technical aspects of this environment. We also briefly report first experiences with this type of multi-media environment sessions in the school.

Keywords: Humanoid robot; autistic children; interaction play; music therapy; robot playmate

\section{Background and related research}

Autism, contemporarily classified as Autistic Spectrum Disorder [1], is a neuro-developmental disorder that has a strong impact on personal and family life [2], [3], [4]. There are unanswered questions about autism related to its etiology, therapy and treatment. In recent years, research in the field of autism has become more and more popular due to an increase of epidemiological evidence [5]. The characteristics of autism include impaired social interaction and communication, and repetitive behaviors and imagination [6], [7]. Due to the fact that autism might influence all aspects of human functioning, finding adequate therapeutic treatments is necessary to improve the well-being of autistic persons as well as their families. However, using a 2015 National Center of Autism report as a reference [8], it should be pointed out that effective therapy procedures in autism are based on behavioral and cognitive-behavioral approaches. Other methods, such as art therapy, music therapy, and sensory integration, available for autistic person treatment might be used as additional and supportive methods.
Play therapy is a form of counseling or psychotherapy that uses an interaction game to communicate with people and help them, especially children [9]. Play therapy is used to improve social integration, growth and development. It is generally employed on children between the ages of three and eleven. Therefore, we assume that letting robots play with autistic children is a good way to improve their social and communication skills [10], [11], [41].

Music therapy is a professional area that completes an approved music therapy program by a music therapist [12]. Music therapy can improve several aspects of personal and social functioning, such as mental functioning, motor skills, emotional development, social skills, and quality of life. Patients can get a feeling for the music by listening, singing, playing instruments, and moving. Music therapy for children is conducted either in a one-on-one session or in a group session. It can help children who have problems with communication, attention, and motivation, as well as with behavioral problems [13].

Music therapy treatment for children with autism might be useful in many cases [14-16]. However, therapists need mediators to treat autistic children in 
general because autistic children cannot react to humans properly and do not learn in socially mediated contexts in the same manner as others [17].

Autistic children are impaired in communication and social skills and thus might be afraid of people because they do not find people to be intentional and rational agents [18]. Treating others as rational agents who have their own beliefs and desires and other mental states is conceptualised as the theory of mind ability [19], which is impaired in autism because of untypical prenatal development of the brain [20], [21]. Due to this fact, using a robot to cure autistic children can be a good choice. To an autistic child, a robot is less intimidating and more predictable than a human. It can do the same procedure repeatedly and will not get tired. There are also some researches that show that robots indeed are attractive to autistic children [22-24] due to the facts that systemizing is the dominant cognitive process in autism and robot gaze monitoring is more engaging than that of human agents [25].

There are also some researches [26-29] that conclude that the music influences autistic children. Therefore, music interaction between autistic children and robots may be a good intervention [30].

\section{Research of Human-Robot Interactions}

In 1998 Kerstin Dautenhahn, lain Werry, John Rae, et al. [33] started using robots to help autistic children. Their project is called "The AuRoRA Project" and has been executed for over 10 years. One of their former experiments was using a wheeled robot, Labo-1 [33]. Labo-1 has 8 infrared sensors, four in its front and four in its back. This robot also has a temperature sensor and a speaker. It can do some behaviors, such as obstacle avoidance and child tracking.

The group also developed many different types of robots one by one to support the Aurora project. The following robots are being used: Pekee robot, an upgraded version of Labo-1; Robota robot, a humanoid doll robot which has an infrared sensor and some rotatable joints; KASPAR, a humanoid robot that has many movable joints (over 11 ) and tactile sensors, and its eyeballs are rotatable. There are some researches that got good results when KASPAR interacted with autistic children by tactile interaction [23], [24].

There are also some robots for human-robot interactions (HRI) [34-37]. Paro is a seal-like robot that has five kinds of sensors that can perceive people and the surrounding environment. Paro is now always used to accompany elderly people. Huggable has more than 1500 sensors on its skin to feel the environment, and its appearance is like a teddy bear. NeCoRo is a robot that looks like a real cat, and it has 7 sensors that let it know of touches from the environment. We can see that more and more robots are made to accompany or take care of humans.
The ongoing developments of small size robots are more flexible and more robust with the advance of corresponding technologies. There are more and more organizations devoted to this field of research. One group at the University of Connecticut has published a paper [13] that mentions they use Aldebaran's NAO robot to play with autistic children via rhythmic music playing interaction with a drum. They consider that this may be a form of mimicry, which is an important social skill [38], [39].

\section{Interpersonal Synchrony}

Human beings are social animals, so their relationships among peers are very important. Interpersonal synchrony is a dynamic process that develops from the interplay between the members of a group. It seems to be a very usual way for typically developed people to get along with others. They mutually influence each other as they move together, and this creates an emergent synchronous system that is selforganizing. Synchronous activities can lead people to cooperate with others and can improve the feelings of affiliation [38]. However, autistic children do not have this ability to adapt to their social environments, and this affects how they get along with their classmates and parents. Therefore, mimicry became the main goal of our experiment.

We wanted to determine whether letting autistic children imitate a robot's behaviors is a feasible way to improve their ability to mimic. Finally, we decided to have a robot play an instrument and designed an interaction game between the robot and autistic children.

We assumed that autistic children can learn the ability of mimicry through the experiment.

\section{Method}

\section{Hardware and Software}

\section{DARwIn-OP}

DARwIn-OP is made by ROBOTIS, and it is an open architecture robot. Since it is open architecture, we can easily change the framework and program. We have also found enough software resources on the internet. DARwIn-OP has a camera, two microphones, a speaker, a gyroscope sensor, three buttons and 20 DOF. It uses Dynamixel RX-28 motors and every motor has its own ID. We can control the state of $s$ motor by the ID and complete the task that we want the robot do. In our experiment, we used the Darwin-OP as our robot playmate.

\section{Environment}

Figure 1 shows the whole session environment. A laptop is used to control the robot, and it sends its 
messages through wireless access point. We also use a laptop to analyze the sound that was recorded by the external microphone, and then send instructions to the robot to play the corresponding note. The vibraphone was decided as the child's instrument at first, but the echo of a vibraphone is too long and too loud, and we could not predict the child's behavior. Therefore, we chose a xylophone to be the child's instrument. Cameras can be used to record all the time. The teacher and the experimenter sit beside the child so that they can take care of the child and give help.
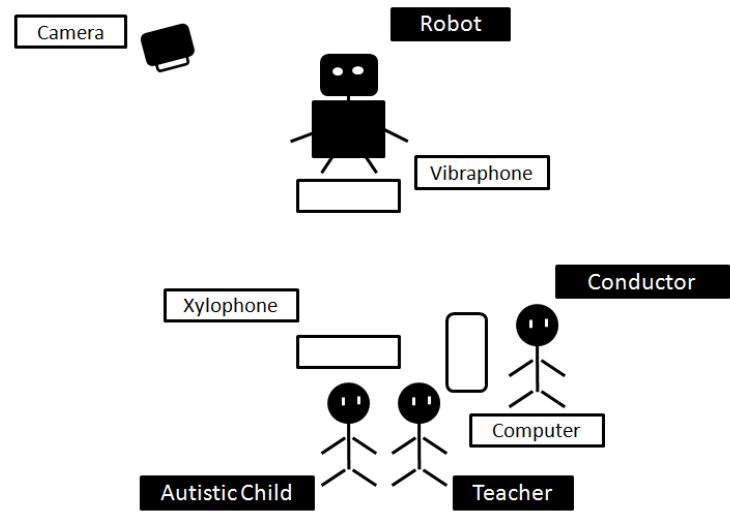

Figure 1. The environment of the experiment. We use a robot, a laptop, a vibraphone, a xylophone, and a camera to complete our experiment.

\section{Programming procedure}

The console system is programmed in $\mathrm{C}++$. The UDPbased Data Transfer Protocol (UDT) handles wireless communication between the laptop and Darwin-OP. We use the SFML library to record and obtain the data of the sound. We have to record the sound continuously until the imitation part ends. Therefore, we analyze the sound every 1 second and use two threads to implement this part. Figure 2 shows the procedure of the program. The data will be put into a band-pass filter at first. Then a window will be used to cut the data into many frames. The window size is decided through testing; 8192 was chosen as the appropriate widow size. An FFT is used to analyze the data. Then the power spectrum is compared to the threshold. If the power is bigger than the threshold, the result will be sent to the robot; otherwise the next window will be checked. The sequence of tunes is sent to the robot. Each note has its actions, so the computer will send the corresponding action order to the robot. As a result, the robot will play the notes in the same sequence as the child.

\section{Procedure}

Every session takes about 10-15 minutes, which can be modified according to the child's situation and mood. One session works in three stages.

\section{Interaction part}

Figure 3 shows the procedure of the experiment. At the beginning, the robot plays a song to attract the student's attention. Since it is hard for autistic children to concentrate on one thing, it is a very important step in this experiment. Then the child is allowed to play the instrument freely in the second phase. The robot will imitate the child's action and play the same notes as the child played. In the second phase, we think that it is interesting that they he robot will play the same music as the child just played. The third phase is the most difficult phase in the experiment. After the robot imitates their action, we need the child to imitate the robot in turn.

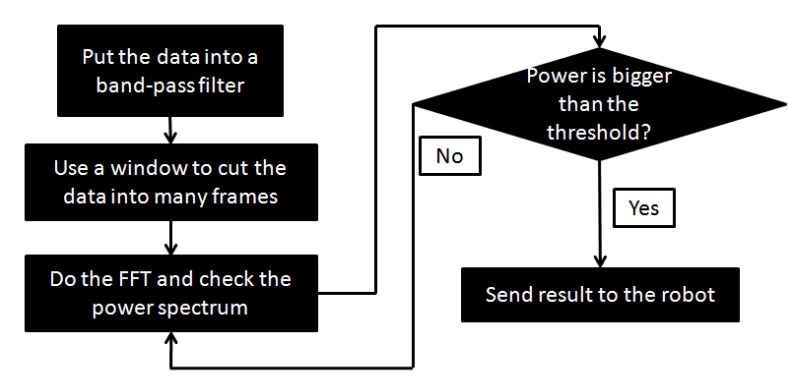

Figure 2. The procedure of the program. The data will be put into a bandpass filter at first. Then a window will be used to cut the data into many frames. An FFT is used to analyze the data. If the power spectrum is bigger than the threshold, the result will be sent to the robot. Otherwise the next window will be checked.

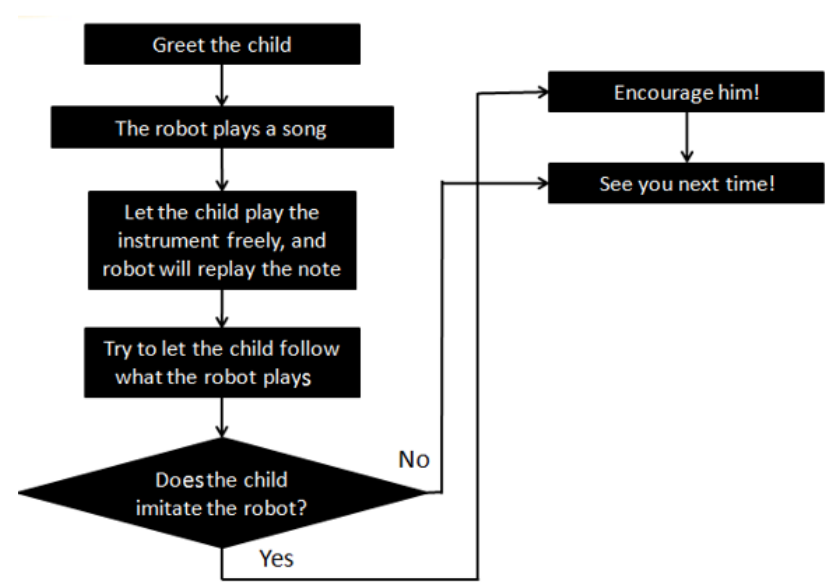

Figure 3. The flow chart of the experiment. The robot plays a song at first. Then the child plays the instrument and the robot will imitate him/her. In the next phase, the child has an opportunity to imitate the robot, and we will see the result.

Research aims were to determine if the child's mimicry ability and turn-taking ability increased after a robot mediated music procedure. Participants

The first round of therapy sessions have been completed with two students of a special care elementary school in the Yunlin prefecture of Taiwan. Both of them show symptoms of severe autism. As a consequence they show severe impairments in verbal communication. One of them is a girl (Shan), and the other is a boy (Ming). The teacher told us that both of them like to play instruments and they are both 8 years old. Shan is a moody girl, and 
she likes to make new experiences. She has the habit of biting her fingers and pinching her face when she is angry. Ming is a passive boy and loves music, warm hugs and kisses. He pounds the table vigorously or pushes things down when he is angry. In addition to his autism, he has been diagnosed with epilepsy.

\section{Sessions}

Sessions were undertaken in a weekly fashion and lasted about 45 minutes, depending on the apparent interest of the particular student.

We noticed that Ming improved every week. At the beginning he didn't look at the robot. At the end of the experimental session time, he would look at it sometimes. Although we cannot be sure that he knew the robot imitated him, we could observe that he noticed the robot and that the robot will play its instrument when he plays the xylophone. Most obviously, during week 4, he started to look at the robot, and he also performed well in week 5. However, he had a seizure on the morning of the week 6 session and felt uncomfortable. He didn't do well and was a little distracted during the experiment, but this can be appreciated. Although he was a little upset, he still performed well and steady in week 7 . We had a little surprise about the reaction during the third part of the sessions. He looked at the robot sometimes and then he hit the table or played the xylophone once or twice. This discovery brings us much confidence in the experiment. The teacher and we believe that further improvements are likely if we continue the sessions.

The results from Shan were not as good as the results from Ming. She did very well the first time, and the teacher said that she loved the novelty. We could observe that her performance became worse and worse every week through week 5 . The teacher said that maybe she was in a bad mood because she had a short nap. We could see that she even had to be strongly motivated to play the xylophone in week 4 . We could not obtain much progress during week 6 and week 7 of our sessions.

\section{Discussion}

It was assumed that autistic children can learn the ability of mimicry through the presented experiment. Based on our findings we could conclude that playing with a robot seems to be engaging to autistic children. This follows previous results [20], [21]. Our assumption was positively verified, however, the practical effects require a very long intervention to improve the functioning of an autistic person. This preliminary experimental proposal of robot mediated music therapy might extend the supporting method spectrum, which is based on puppets and music [12], [40]. However, the symptoms of autism vary from person to person, so it is hard to design a method which can be used with every autistic child. Nevertheless, it might be stated that the proposal presented in the paper can make a positive but limited impact on autistic children. Pros and cons of a robot mediated approach should be analyzed more intensely.

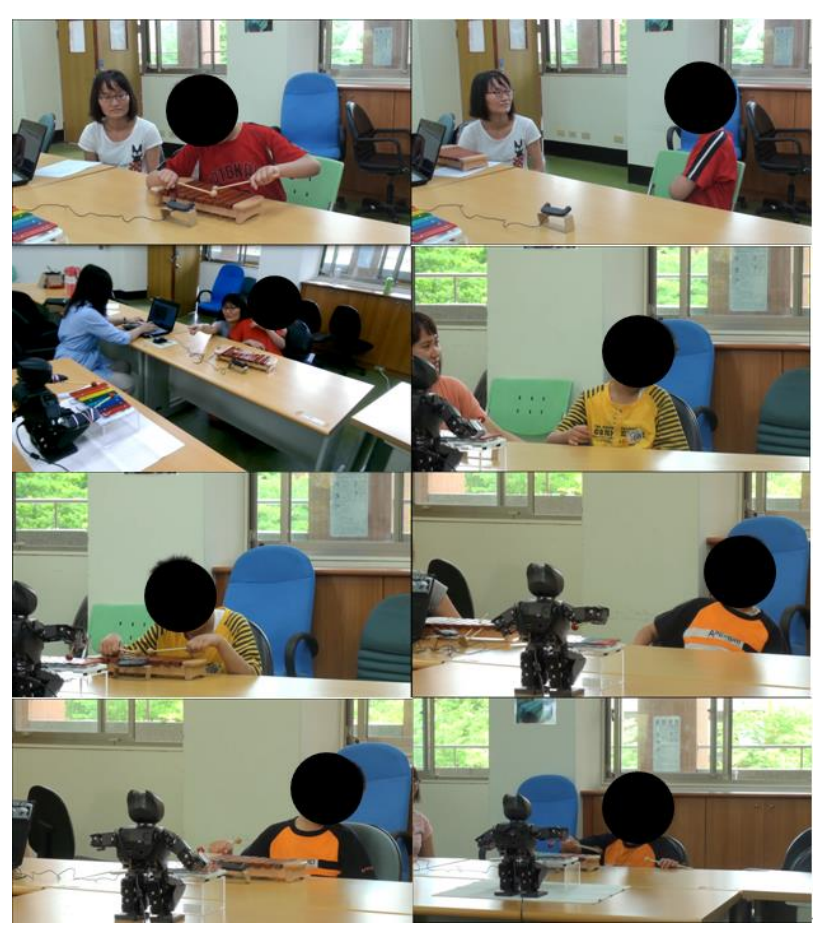

Figure 4. The scene sequence of one student's reaction and behavior during s session.

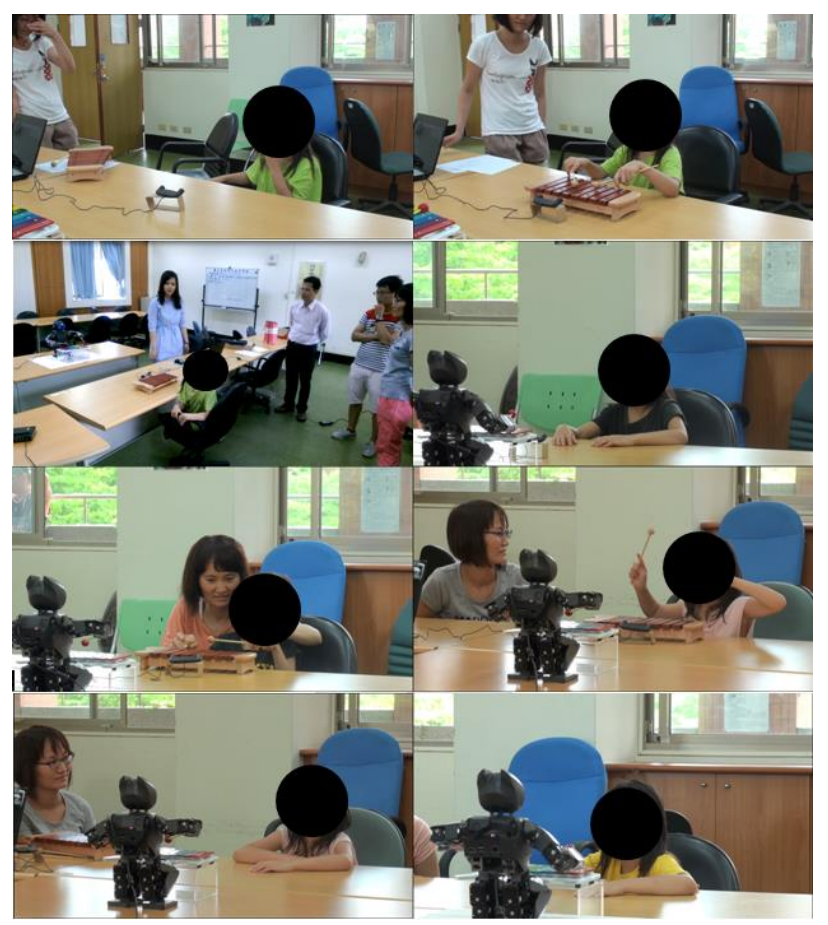

Figure 5. The scene sequence of a girl during class.

\section{Acknowledgements}

We thank the students and the teacher from National Yunlin Special School. We also thank IRCAD TAIWAN Training Center and AIM-HI for the provided technology, medical knowledge and financial help. 


\section{References}

[1] Diagnostic and statistical manual of mental disorders, 5th ed., American Psychiatric Association, Washington, DC, USA, 2013.

[2] L. Smith and J. Elder, "Siblings and family environments of persons with austism spectrum disorder: a review of the literature," J. Child Adolesc. Psychiatr. Nurs., vol. 23, no. 3, pp. 189-195, Aug. 2010.

doi: $10.1111 / \mathrm{j} .1744-6171.2010 .00240 . x$

[3] K. D. Sage and B. Jeqatheesan, "Perceptions of siblings with autism and relationships with them: European American and Asian American siblings draw and tell," J. Intellect. Dev. Disabil., vol. 35, no. 2, pp. 92-103, Jun. 2010. doi: $10.3109 / 13668251003712788$

[4] T. Tomeny, B. M. Ellis, J. A. Rankin, and T. B. Barry, "Sibling relationship quality and psychosocial outcomes among adult siblings of individuals with autism spectrum disorder and individuals with intellectual disability without autism," Res. Dev. Disabil., vol. 62, pp. 104-114, Mar. 2017. doi: 10.1016/j.ridd.2017.01.008

[5] "Community report from the autism and developmental disabilities monitoring (ADDM) Network," 2012. Available:

http://www.cdc.gov/ncbddd/autism/documents/A DDM-2012-Community-Report.pdf

[6] S. E. Levy, D. S. Mandell, and R. T. Schultz, "Autism," Lancet., vol. 374, no. 9701, pp. 1627-1638, Nov. 2009.

doi: 10.1016/S0140-6736(09)61376-3

[7] I. Rapin and R. F. Tuchman, "Autism: definition, neurobiology, screening, diagnosis," Pediatric Clinics of North America, vol. 55, no. 5, pp. 1129-1146, Oct. 2008.

doi: $10.1016 /$ i.pcl.2008.07.005

[8] Report, National Autism Center, 2015. Available: http://www.nationalautismcenter.org/nationalstandards-project/results-reports/

[9] G. L. Landreth, "Play therapy: The art of the relationship," Munice, IN: Accelerated Development, 1991.

[10] G. L. Landreth, L. Homeyer, G. Glover, and D. Sweeney, "Play therapy interventions with children's problems," Northvale, NJ: Jason Aronson, 1996.

[11] S. Bratton, D. Ray, T. Rhine, and L. Jones, "The efficacy of play therapy with children: A metaanalytic review of the outcome research," Professional Psychology: Research and Practice, vol. 36, no. 4, pp. 375-390. Aug. 2005.

[12] T. Wigram, "Methods and Techniques for Music
Therapy Clinicians, Educators, and Students," Jessica Kingsley, London, 2004.

[13] T. Gifford, S. Srinivasan, M. Kaur, D. Dotov, C. Wanamaker, G. Dressler, and A. Bhat, "Using Robots to Teach Musical Rhythms to Typically Developing Children and Children with Autism, "University of Connecticut, 2011.

[14] K. Simpson and D. Keen, "Music Interventions for Children with Autism: Narrative Review of the Literature," J. Autism Dev. Disord., vol. 41, no. 11, pp. 1507-1514, Nov. 2011. doi: $10.1007 / \mathrm{s} 10803-010-1172-y$

[15] P. Vaiouli and H. Schertz, "Promoting Social Engagement for Young Children with Autism: A Music Therapy Approach," in Proceeding of the $12^{\text {th }}$ International Conference on Music Perception and Cognition, Thessaloniki, Greece, 2012.

[16] E. Masiak, "Improvisational music therapy as a method of enhancing social interaction and communication skills in autism spectrum disorders," Presentation on International Scientific Conference AUTISM SPECTRUM - SPECTRUM OF METHODS. RESEARCH AND PRACTICE, Krakow, Poland ,2013.

[17] L. S. Vygotsky, "Mind in society: The development of higher psychological processes," Harvard university press, 1980.

[18] T. O'Connor and D. Robb, “True believers: the intentional strategy and why it works," In Philosophy of Mind: Contemporary Readings, London, England: Routledge, 2003, pp. 370-390.

[19] S. Baron-Cohen, A. M. Leslie, and U. Frith,"Does the autistic child have a 'theory of mind'?," Cognition, vol. 21, no. 1, pp. 37-46, Oct. 1985. doi: 10.1016/0010-0277(85)90022-8

[20] S. Baron-Cohen, "The extreme male brain theory of autism," Trends Cogn. Sci., vol. 6, no. 6, pp. 248-254, Jun. 2000.

doi: 10.1016/S1364-6613(02)01904-6

[21] N. Goldenfeld, S. Baron-Cohen, S. Wheelwright, C. Ashwin, and B. Chakrabarti, "Empathizing and systemizing in males, females and autism: A test of the neural competition theory," In Empathy in Mental Illness, Cambridge University Press, 2007, pp. 322-334. doi: $10.1017 /$ CBO9780511543753.019

[22] J. Wainer, K. Dautenhahn, B. Robins, and F. Amirabdollahian, "Collaborating with Kaspar: Using an autonomous humanoid robot to foster cooperative dyadic play among children with autism. In Humanoid Robots (Humanoids)", in Proceeding of International Conference on Humanoid Robots (Humanoids), Nashville, TN, USA, 2010. doi: $10.1109 /$ ICHR.2010.5686346

[23] B. Robins, K. Dautenhahn, and P. Dickerson, 
"Embodiment and Cognitive Learning-Can a Humanoid Robot Help Children with Autism to Learn about Tactile Social Behaviour?," In Proceeding of The $6^{\text {th }}$ International Conference on Social Robotics, Chengdu, China, 2012, pp. 66-75.

[24] S. Costa, H. Lehmann, B. Robins, K. Dautenhahn, and F. Soares, "Where is your nose? - Developing body awareness skills among children with autism using a humanoid robot," in Proceeding of International Conference on Advances in Computer-Human Interactions, Nice, France, 2013.

[25] E. Wiese, H. J. Müller, and A. Wykowska, "Using a Gaze-Cueing Paradigm to Examine Social Cognitive Mechanisms of Individuals with Autism Observing Robot and Human Faces," In Proceeding of The $6^{\text {th }}$ International Conference on Social Robotics, Sydney, NSW, Australia, 2014, pp. 370-379.

[26] C. L. Edgerton, "The effect of improvisational music therapy on the communicative behaviors of autistic children," Journal of Music Therapy, vol. 31, no. 1, pp. 31-62, Mar. 1994.

[27] J. Kim, T. Wigram, and C. Gold, "The effects of improvisational music therapy on joint attention behaviors in autistic children: a randomized controlled study," J. Autism Dev. Disord., vol. 38, no. 9, pp. 1758-1766, Oct. 2008. doi: $\underline{10.1007 / s 10803-008-0566-6}$

[28] K. Dautenhahn and I. Werry, "Issues of robot-human interaction dynamics in the rehabilitation of children with autism," in From Animals to Animats 6: Proceeding of the $6^{\text {th }}$ International Conference on Simulation of Adaptive Behavior (Complex Adaptive Systems), $1^{\text {st }}$ ed., a Bradford book, 2000, pp. 519-528.

[29] The AuRoRA Project. Available: www.aurora-project.com (accessed 18 June 2014)

[30] F. Michaud and C. Théberge-Turmel, "Mobile robotic toys and autism," In Socially Intelligent Agents, vol.
3, Boston, MA, USA: Springer, 2002, pp. 125-132.

[31] R. Cassidy, B. Cote-Dumphy, J. S. Lee, and W. Mitchell-Evans, "Why do people imagine robots," Worcester Polytechnic Institute, 2009.

[32] "Toy Story" movie series. (1995, 1999 and 2010). Walt Disney Pictures.

[33] K. Dautenhahn and I. Werry, "Towards interactive robots in autism therapy: Background, motivation and challenges," Pragmatics \& Cognition, vol. 12, no. 1, pp. 1-35, Jun. 2004. doi: $10.1075 / p c .12 .1 .03$ dau

[34] Robot Paro. Available at www.parorobots.com (accessed 18 June 2014)

[35] Teddy bears Huggable. Available at robotic.media. robotic.media.mit.edu/projects/robots/huggable/o verview/overview.html (accessed 18 June 2014)

[36] Cat NeCoRo Available at megadroid.com/Robots/ necoro.htm (accessed 18 June 2014)

[37] C. Becker-Asano, K. Ogawa, S. Nishio, and H. Ishiguro, "Exploring the uncanny valley with Geminoid HI-1 in a real-world application. In Proceedings of IADIS International Conference Interfaces and Human Computer Interaction, Freiburg, German, July 2010, pp. 121-128.

[38] M. J. Hove and J. L. Risen, "It's all in the timing: Interpersonal synchrony increases affiliation,"Social Cognition, vol. 27, no. 6, pp.949-960, 2009. doi: $10.1521 /$ soco.2009.27.6.949

[39] M. Kinsbourne and M. Helt, "Entrainment, mimicry, and interpersonal synchrony," The Neuropsychology of Autism, Oxford Univ. Pr., 2011, pp. 339-365.

[40] P. Dobson and N. Abbotts, "How puppetry helps pupils on the autism spectrum," Good Autism Practice (GAP), vol. 9, no. 2, pp. 26-31, 2008.

[41] E. Barakova, J. Gillessen, and L. Feijs, "Social training of autistic children with interactive intelligent agents," Journal of Integrative Neuroscience, vol.8, no.1, pp. 23-34, Mar. 2009. 